\title{
Type 1 diabetes is increasing in very young children, but is the real reason referable only to environmental factors?
}

\author{
Andrea E. Scaramuzza • Gian Vincenzo Zuccotti
}

Received: 24 November 2011/Accepted: 15 December 2011/Published online: 30 December 2011

(C) Springer-Verlag 2011

In spite of intensive research in recent decades, the causative factors of type 1 diabetes remain unknown. To some extent the disease is genetically influenced, and mostly by certain MHC types. However, $90 \%$ of patients with type 1 diabetes have no first-degree relatives, and the pairwise concordance rate for monozygotic twins is $<30 \%$ [1]. In any event, type 1 diabetes is a disease in which the environment plays a major role [2]. So far, the real factor(s) involved are still unknown, but many are put forward from time to time.

In this issue of the journal, you can read the paper by McNamee et al. [3], which found weak evidence of increased risk of type 1 diabetes in children who had neonatal jaundice (OR 1.14; 95\% CI 0.99-1.32; $P=0.07$ ), with some evidence of heterogeneity $\left(I^{2}=53 \%, P=0.01\right)$. The authors conclude that jaundice caused by blood group incompatibility or requiring phototherapy may be associated with a greater increase in type 1 diabetes risk and deserves further study.

Several papers have been published on this topic (neonatal factors associated with an increased risk of type 1 diabetes), most of which have been evaluated by two metaanalyses [4, 5]. The first found that increased birth weight is associated with childhood onset, equivalent to a $7 \%$ increase in risk for every $1,000 \mathrm{~g}$ in weight [4], and the second reported that caesarean section increases the risk by around $20 \%$ [5]. A more recent paper provides formal confirmation that the risk of childhood onset diabetes increases with maternal age: $5 \%$ for each 5 years of age [6].

Why should neonatal jaundice influence the risk of diabetes in children? There is much speculation, but the main

A. E. Scaramuzza $(\bowtie) \cdot$ G. V. Zuccotti

Department of Paediatrics, University of Milano,

"Luigi Sacco Hospital”, via G.B. Grassi 74, 20157 Milan, Italy

e-mail: scaramuzza.andrea@hsacco.it explanation is that blood group incompatibility may be the most important factor, together with the practice of phototherapy, used to treat the more severe cases of jaundice, which may itself be a risk factor. An increased frequency of the DR3 allele was observed also in patients with AB0 incompatibility when compared to healthy controls [7]. In their study, Berzina et al. [7] observed that patients with type 1 diabetes had a significantly higher frequency of DR3, DQ2, DR4 and DQ8 alleles when compared to healthy controls, while no significant difference was observed in frequency of DR3 between AB0 blood group incompatibility and type 1 diabetes patients, leading to the conclusion that DR3 is associated with both the development of type 1 diabetes and ABO incompatibility. This might be the reason for increased risk of childhood diabetes in patients with neonatal jaundice, often due to AB0 incompatibility.

The truth is that the rise of childhood type 1 diabetes remains largely unexplained [8, 9], and possibly, it is not the only kind of diabetes affecting young patients. Indeed, we are accustomed to diagnosing type 1 diabetes whenever we treat a child with 'high blood sugar levels', as if hyperglycaemia in children always means type 1 diabetes, overlooking the existence of many other forms of diabetes that do not require insulin, for example, monogenic diabetes, mitochondrial diabetes or type 2 diabetes in adolescents [10].

For many years, a differential diagnosis of hyperglycaemia in children has been difficult because of the lack of suitable diagnostic tools: specific autoantibodies, molecular biology techniques, genetic mapping, etc. In the last two decades, an explanation of the pathogenic mechanisms of most forms of hyperglycaemia in children clearly demonstrated that not all of them are due to type 1 diabetes.

We have attempted to better define differential diagnosis. On the one hand, papers like the one by McNamee 
et al. [3] help us to better understand the pathogenic cause of type 1 diabetes. On the other hand, we need to open our minds so we are able to identify further clues.

\section{References}

1. Knip M (2011) Pathogenesis of type 1 diabetes: implications for incidence trends. Horm Res Paediatr 76(suppl 1):57-64

2. Buschard K (2011) What causes type 1 diabetes? Lessons from animal models. APMIS 119:1-19

3. McNamee MB, Cardwell CR, Patterson CC (2011) Neonatal jaundice is associated with a small increase in the risk of childhood type 1 diabetes: a meta-analysis of observational studies. Acta Diabetol. doi:10.1007/s00592-011-0326-5

4. Cardwell CR, Stene LC, Joner G et al (2008) Caesarean section is associated with an increased risk of childhood-onset type 1 diabetes mellitus: a meta-analysis of observational studies. Diabetologia 51:726-735

5. Harder T, Roepke K, Diller N et al (2009) Birth weight, early weight gain, and subsequent risk of type 1 diabetes: systematic review and meta-analysis. Am J Epidemiol 169:1428-1436

6. Cardwell CR, Stene LC, Joner G et al (2010) Maternal age at birth and childhood type 1 diabetes: a pooled analysis of 30 observational studies. Diabetes 59:486-494

7. Berzina L, Ludvigsson J, Sadauskaite-Kuehne V et al (2002) DR3 is associated with type 1 diabetes and blood group $\mathrm{ABO}$ incompatibility. Ann N Y Acad Sci 958:345-348

8. Gale EAM (2002) The rise of childhood type 1 diabetes in the twentieth century. Diabetes 51:3353-3561

9. Patterson CC, Dahlquist GG, Gyürüs E, EURODIAB Study Group et al (2009) Incidence trends for childhood type 1 diabetes in Europe during 1989-2003 and predicted new cases 2005-20: a multicentre prospective registration study. Lancet 373:2027-2033

10. Iafusco D, Scaramuzza AE, Galderisi A et al (2011) Not every child with diabetes needs insulin. BMJ 341:c6512 